Original Article

\title{
Association of Cigarette Smoking with Hearing Loss in Young Male Adults of Hyderabad, Pakistan
}

Shakil Ahmed Shaikh, Zulfiqar Ali Laghari, Salma Farrukh Memon, Muhammad Ali Bhatti

\section{ABSTRACT}

OBJECTIVE: To evaluate the effects of cigarettes smoking on hearing loss in young adult's aged $\leq 35$ years.

METHODOLOGY: This cross-sectional research was carried out in the ENT department of Combined Military Hospital Hyderabad. The hearing loss was assessed by Audiometry, Whisper test, Rinne's test and Webbers test. The young healthy adults with no known history of exposure to extreme noise were included. All the participants which had any type of infections or any otic injury were excluded from study. The audiometry was performed on the audiometer MAICO-MA39 (Berlin Germany) at Combined Military Hospital Hyderabad.

RESULTS: In this study, 148 apparently healthy participants were selected, out of 148,73 were smokers and 75 were nonsmokers. The age of the participants ranged between 20 to 35 years with the mean age of smokers $28.99 \pm 3.731$, and nonsmokers $28.00 \pm 4.451$ non-smokers. The data collected indicate significantly higher prevalence of hearing loss in smokers $49.31 \%, P<0.01$ than in non-smokers (30.66\%). Age of smokers was positively correlated $(r=0.427, P<0.01)$ with hearing loss. Frequency of cigarettes smoked per day was positively correlated $(r=0.715, P<0.01)$ and year of smoking was also positively correlated with hearing loss $(r=0.620)$. The correlation of frequency of cigarette smoking and duration of smoking with hearing level was extremely significant $(P<0.01)$.

CONCLUSION: These findings suggest that cigarette smoking is associated with hearing loss in young adults; this study will be helpful in making public health policies.

KEY WORDS: Hearing Loss, Cigarette Smoking

This article may be cited as: Shaikh SA, Laghari ZA, Memon SF, Bhatti MA. Association of Cigarette Smoking with Hearing Loss in Young Male Adults of Hyderabad, Pakistan. J Liaquat Uni Med Health Sci. 2018;17(04):230-4. doi: 10.22442/jlumhs.181740583

\section{INTRODUCTION}

Hearing loss is the major cause of public health concern, affecting millions irrespective of gender and health around the world ${ }^{1,2}$. The outcome of untreated hearing impairment incorporate decrease wellbeing related personal satisfaction in population, increasing the risk of occupational and non-occupational injuries and hearing ability too ${ }^{3}$. The World Health Organization has assessed that there are around 360 million individuals with hearing loss across the world and hearing loss is the 15th greatest cause of the burden of disease as disability adjusted life years (DALYs) in both genders and all ages ${ }^{4}$. The factors associated with the hearing loss are increasing $a^{5} \mathrm{e}^{5}$, occupational noise ${ }^{6,}$ medication addiction ${ }^{7}$, ear infections $^{8}$ and cigarette smoking ${ }^{9}$.

Smoking is a major factor for a number of complications which include different types of cancers $^{10}$, cardiovascular disease ${ }^{11}$, respiratory complications ${ }^{12}$ gastric and duodenal ulcers ${ }^{13}$ hearing impairment ${ }^{9}$. The mechanism of action has not been extensively studied except some studies which suggest cigarette smoking may also affect cochlear blood supply because it causes peripheral vascular changes, such as increased blood viscosity, and reduced available oxygen. These effects were identified in the etiology of cochlear lesions in laboratory animals and humans ${ }^{14}$. The recent statistics showed that the smokers are $70 \%$ more likely to develop some forms of hearing impairment than in non-smokers. The latest research demonstrated that the smokers are $70 \%$ more prone to build up a few types of hearing loss than in non-smokers. Age itself is a non-modifiable factor causing hearing loss, in older age group however, young adults might suffer hearing loss due to modifiable factors such as cigarette smoking ${ }^{15}$. Hearing loss has not been extensively studied in Pakistan, few studies have been reported from Pakistan indicating noise induced effects on hearing ${ }^{16-18}$. However, the data on effects of cigarette smoking on hearing is scarce, whereas cigarette smoking is common in all age groups particularly young adults ${ }^{19-21}$.

The purpose of this study was to assess the hearing loss in smokers and nonsmokers in young healthy 
adults residing in different areas of Hyderabad, Pakistan, who were not exposed to extreme noise and did not have any secondary infection.

\section{METHODOLOGY}

This cross-sectional research conducted from June 2016 to December 2016 in Hyderabad city of Sindh Pakistan. In this study, we included the participants having history of smoking not less than five years. In this study simple, random technique was used for data collection. The data was gathered through interview by structured questionnaire that include Socio demographic, education standard, medical screening, history of chronic illnesses, cigarette smoking history. Total 200 young adult smokers $(n=100)$ and nonsmokers $(n=100)$ were randomly recruited from of Hyderabad city. After filling of interview based questionnaire, participants taking or with history of taking ototoxic medications, erythromycin, amino glycoside, quinoline anti-malarial, macrolide antibiotics, loop diuretics, platinum analog antineoplastics and acetylsalicylic acid, Participants suffering from repeated ear infections and discharge excluded. Subjects suffering from congenital ear deformity and all cases of conductive deafness excluded from research. Subjects with the history of hypertension, diabetes mellitus, participants who are already suffering from deafness and nerve deafness in family and on medication that impair hearing function were excluded from research.

Written and verbal consent was obtained from participants; all the queries of participants were addressed. Whisper test, Rinnie's test, Webbers test performed on all 200 subjects of both groups to exclude disorders e.g. ear trauma, infection, ear discharge, sensorinueral problems, conductive hearing impairment and any congenital deformity. The Audiometry performed on Audiometer MAICO-MA39 (Berlin Germany). The air conduction threshold measured and graph plotted on audiogram.

The collected data was analyzed on SPSS 16.0. Group variances were calculated. The $p$-value at $<0.5$ was set as significance level and at $<.01$ as extremely significant. Pearson chi square test and Pearson correlation, frequencies and percentage were calculated for qualitative and quantitative data.

\section{RESULTS}

Total 200 participants were randomly selected, however only 148 finally participated in the study, giving the response rate of $74 \%$. The mean age of smokers was $28.99 \pm 3.731$ and the mean age of nonsmokers was $28.00 \pm 4.451$. Out of $148,49.32 \%$ $(n=73)$ were smokers and $50.68 \%(n=75)$ were nonsmokers. The mean hearing level was higher in smokers $(22.71 \pm 11.365 \mathrm{~dB})$ than in non-smokers $(15.91 \pm 7.374 \mathrm{~dB})$.

Out of 73 smokers, $49.31 \%(n=36)$ had hearing loss, and $50.59 \% \quad(n=37)$ had normal hearing, in nonsmokers the hearing loss was $30.67 \%(n=23)$ and $59.33 \% \quad(n=52)$ had normal hearing. The smokers group had significantly higher prevalence of hearing loss $(p<0.01)$ than non-smoker group. According to Table II, the hearing loss was significantly higher in smokers, who smoked $>10$ cigarettes a day that those who smoked $\leq 10$ a day, similarly the smokers who had been smoking cigarettes for more than $>10$ years had significantly higher prevalence of hearing loss than those had been smoking the cigarettes for $\leq 10$ years.

According to Table III bivariate correlation analysis shows that Age of non-smoker was positively correlated $(r=0.045)$ with hearing level, however, it was not statistically significant $(p>0.05)$. However, age of smoker was positively correlated $(r=0.475 P<$ 0.01 ) with hearing level. Strong positive correlation with statistical significance $(r=0.715)$ was found between frequency of cigarettes smoked per day and hearing level. Similarly, the duration of cigarette smoking was also strongly positive correlated ( $r$ $=0.620$ ) with hearing level. The correlation was statistically highly significant $(p<0.01)$.

TABLE I: HEARING LOSS IN SMOKERS AND NON-SMOKERS

\begin{tabular}{|l|c|c|c|l|}
\hline Variables & $\begin{array}{c}\text { Normal } \mathbf{~} \\
(\mathbf{\%}) \\
<\mathbf{2 0} \mathbf{~ D b}\end{array}$ & $\begin{array}{c}\text { Hearing } \\
\text { Loss } \mathbf{~ ( \% )} \\
\mathbf{2} \mathbf{2 0} \mathbf{~ d B}\end{array}$ & $\mathbf{X}^{\mathbf{2}}$ & p Value \\
\hline Smokers & $37(50.68)$ & $36(49.32)$ & \multirow{2}{*}{5.37} & $<0.01$ \\
\hline Non-smokers & $52(69.33)$ & $23(30.67)$ & & \\
\hline
\end{tabular}

TABLE II: DISTRIBUTION OF PARTICIPANTS ACCORDING TO FREQUENCY CIGARETTES AND DURATION OF SMOKING

\begin{tabular}{|c|c|c|c|c|}
\hline Variables & $\begin{array}{c}\text { Normal } n \\
\quad(\%) \\
<20 \mathrm{~dB}\end{array}$ & $\begin{array}{l}\text { Hearing } \\
\text { Loss } n(\%) \\
>20 \mathrm{~dB}\end{array}$ & $x^{2}$ & p Value \\
\hline \multicolumn{5}{|c|}{ Frequency of Cigarettes } \\
\hline$\leq 10$ & $30(90.91)$ & $3(9.09)$ & \multirow{2}{*}{38.98} & \multirow{2}{*}{$<0.01$} \\
\hline$>10$ & $7(17.50)$ & $33(82.5)$ & & \\
\hline \multicolumn{5}{|c|}{ Duration of Smoking (Years) } \\
\hline$\leq 10$ & $37(62.71)$ & $22(37.29)$ & \multirow{2}{*}{17.8} & \multirow{2}{*}{$<0.01$} \\
\hline$>10$ & $0(00)$ & $14(100)$ & & \\
\hline
\end{tabular}


TABLE III: THE BIVARIATE CORRELATION ANALYSIS BETWEEN THE AGE OF SMOKERS AND NONSMOKERS, FREQUENCY OF CIGARETTES AND DURATION OF SMOKING AND HEARING LEVEL

\begin{tabular}{|l|c|c|}
\hline \multicolumn{1}{|c|}{ Variables } & $\begin{array}{c}\text { Pearson } \\
\text { Correlation }\end{array}$ & p value \\
\hline Age of Smokers & $r=0.427$ & $<0.01$ \\
\hline Age of Non-smokers & $r=0.045$ & $>0.05$ \\
\hline $\begin{array}{l}\text { Frequency of Cigarette } \\
\text { Smoking }\end{array}$ & $r=0.715$ & $<0.01$ \\
\hline Duration of Smoking & $r=0.620$ & $<0.01$ \\
\hline
\end{tabular}

\section{DISCUSSION}

Hearing loss is considered to be major health concern, because more than 360 million of the world population is affected with hearing loss ${ }^{22}$. Hearing loss causes limited meaningful communications and social interactions in society that ultimately leads to reduced quality of life and reduce physical and cognitive impairment. In Public health, it is known that hearing loss is related to depression, diabetes, and dementia. Several studies have been published mainly focusing on synergistic effects of factors such as age and noise along with cigarettes smoking on hearing level. Smoking as an independent factor has not been extensively studied.

Consistent results indicate association of cigarette smoking and hearing impairment in this study. However, mechanism of action of cigarette smoking on hearing loss is not clear, so it is considered that cigarette smoking causes vasoconstriction of blood vessels which decreases blood supply to organ of corti and increases carboxyhaemoblobin that results in damage of hair cells.

The findings in this study suggest that smokers had higher prevalence of hearing loss than nonsmokers; similar findings had been reported from other studies $^{4,23,24}$. The data we present here shows the lesser prevalence of hearing loss than other studies, which reported the hearing loss at $65.7 \%{ }^{23}$. The lesser prevalence in our study might be due the fact that our study included the young healthy adults aged $\leq 35$ years old, who had no known history of noise exposure and secondary ear infection. Although young age group was also reported to have hearing loss even at lesser cigarette smoking ${ }^{25}$.

Our study also suggest that hearing can be affected in the young healthy nonsmoker adults at $\leq 35$ years of age, this is in agreement with previous study which reported that hearing was affected as early as 35 years of age ${ }^{26}$ and with each decade passed the age might affect hearing level in nonsmokers ${ }^{23}$. Strong positive correlation was found in our study between age of smokers and hearing level. Our results are in agreement with previous studies, which reported that combined effects of age and smoking might severely affect the hearing abilities ${ }^{14,24,25,27,28}$. The hearing loss in the young adults is alarming since it might affect the future life of these adults.

We report here that the frequency of cigarette smoking might cause the increase prevalence of hearing loss, several other studies also reported the higher frequency of cigarette smoking as the leading cause of hearing loss ${ }^{4,23,24,29,30}$, however the difference between the sub groups have been found nonsignificant in the study carried out in Bangladesh population $^{27}$, similarly we have also shown that as the frequency of cigarette smoking increases the hearing loss increase. In addition to the frequency of cigarettes smoking, we also report that duration of smoking as the factor for hearing loss as has been reported in other studies ${ }^{23,31-33}$. It was reported, that $100 \%$ of the smokers who smoked for more than 20 years have hearing loss, similarly, we also report here that those who smoker for more than 10 years have hearing loss. Several other studies also reported the similar results ${ }^{4,27,34}$. This suggests that hearing can be affected with both frequency and duration of cigarette smoking. The mechanism of action of effects of cigarette smoking on hearing impairment has not been properly understood and needs further investigation in the future.

\section{CONCLUSION}

Evidence suggests that hearing loss is associated with number of cigarettes smoked per day and duration of cigarettes smoking per day in young male adults. However, cigarette smoking has a weak association in this age group of study.

\section{REFRENCES}

1. Stevens G, Flaxman S, Brunskill E, Mascarenhas $M$, Mathers $C D$, Finucane M. Global and regional hearing impairment prevalence: an analysis of 42 studies in 29 countries. Eur J Public Health 2011; 23(1):146-52. doi: 10.1093/eurpub/ckr176.

2. Mathers C, Smith A, Concha M. Global burden of hearing loss in the year 2000. Global burden of Disease. Geneva: World Health Organization 2003; 18(4):1-30. Available at http://www.who.int/ healthinfo/statistics/bod_hearingloss.pdf

3. Fabry DA, Davila EP, Arheart KL, Serdar B, Dietz NA, Bandiera FC, et al. Secondhand smoke exposure and the risk of hearing loss. Tob Control 2011; 20(1):82-5. doi: 10.1136/tc. 2010. 035832.

4. Nomura K, Nakao M, Morimoto T. Effect of 
smoking on hearing loss: quality assessment and meta-analysis. Prev Med 2005; 40(2):138-44.

5. Ciorba A, Bianchini C, Pelucchi S, Pastore A. The impact of hearing loss on the quality of life of elderly adults. Clin Interv Aging 2012; 7:159-63.

6. ACOEM Task force on Occupational Hearing Loss, Kirchner DB, Evenson E, Dobie RA, Rabinowitz $P$, Crawford J, et al. Occupational noise-induced hearing loss: ACOEM task force on occupational hearing loss. J Occup Environ Med 2012; 54(1):106-8. doi: 10.1097/JOM. 0b013e318242677d.

7. Harris T, Bardien S, Schaaf HS, Petersen L, De Jong G, Fagan JJ. Aminoglycoside- induced hearing loss in HIV-positive and HIV-negative multidrug-resistant tuberculosis patients. S Afr Med J 2012; 102(6 pt 2):363-6.

8. Da Costa SS, Rosito LP, Dornelles C. Sensorineural hearing loss in patients with chronic otitis media. Eur Arch Otorhinolaryngol 2009; 266 (2):221-4. doi: 10.1007/s00405-008-0739-0.

9. Pouryaghoub G, Mehrdad R, Mohammadi S. Interaction of smoking and occupational noise exposure on hearing loss: a cross-sectional study. BMC Public Health 2007; 7(1):137. doi: 10.1186/1471-2458-7-137

10. Blakely $\mathrm{T}$, Barendregt JJ, Foster RH, Hill S, Atkinson J, Sarfati D, et al. The association of active smoking with multiple cancers: national census-cancer registry cohorts with quantitative bias analysis. Cancer Causes Control 2013; 24 (6):1243-55. doi: 10.1007/s10552-013-0204-2.

11. Tan CE, Glantz SA. Association between smokefree legislation and hospitalizations for cardiac, cerebrovascular, and respiratory diseases: a meta analysis. Circulation 2012; 126(18):2177-83. doi: 10.1161/CIRCULATIONAHA.112.121301.

12. Centres for Diseases Control and Prevention (CDC). Chronic obstructive pulmonary disease among adults--United States, 2011. MMWR Morb Mortal Wkly Rep 2012; 61(46):938-43.

13. Zhang L, Ren JW, Wong CC, Wu WK, Ren SX, Shen J, et al. Effects of cigarette smoke and its active components on ulcer formation and healing in the gastrointestinal mucosa. Curr Med Chem 2012; 19(1):63-9.

14. Ferrite S, Santana V. Joint effects of smoking, noise exposure and age on hearing loss. Occup Med 2005; 55(1):48-53.

15. Panigrahi R, Maheshwari A. Prevalence of hearing loss in adolescent smokers. JEMDS 2015; 4(48):8298-8303.

16. Elahi MM, Elahi F, Elahi A, Elahi SB. Paediatric hearing loss in rural Pakistan. J Otolaryngol 1998; 27(6):348-53.
17. Ashraf HD, Younus MA, Kumar P, Siddiqui MT, Ali SS, Siddiqui MI. Frequency of hearing loss among textile industry workers of weaving unit in Karachi, Pakistan. J Pak Med Assoc 2009; 59(8):575-9.

18. Khairi Md Daud M, Noor RM, Rahman NA, Sidek DS, Mohamad A. The effect of mild hearing loss on academic performance in primary school children. Int J Pediatr Otorhinolaryngol 2010; 74 (1):67-70. doi: 10.1016/j.ijporl.2009.10.013.

19. Laghari ZA, Halepota J, Palh ZA, Lashari KH, Baig NM, Menghwar SM, et al. Factors associated with cigarette smoking among male students of colleges of district, Hyderabad, Pakistan. IJoART 2014; 3(12):80-83.

20. Asif HM, Akhtar N, Sultana S, Ahmad K, Qureshi $\mathrm{T}$, Ateeb M, et al. Prevalence and Factors Related to Cigarette Smoking Initiation and Use among University Students of Bahawalpur Pakistan: A Cross Sectional study. RADS Journal of Pharmacy and Pharmaceutical Sciences. 2017; 5 (3):11-6.

21. Nasir K, Rehan N. Epidemiology of cigarette smoking in Pakistan. Addiction 2001; 96(12): 84754.

22. Lozano $R$, Naghavi M, Foreman K, Lim $S$, Shibuya K, Aboyans V, et al. Global and regional mortality from 235 causes of death for 20 age groups in 1990 and 2010: a systematic analysis for the Global Burden of Disease Study 2010. Lancet 2012; 380(9859):2095-128.

23. Kumar A, Gulati R, Singhal S, Hasan A, Khan A. The effect of smoking on the hearing status-a hospital based study. J Clin Diag Res 2013; 7 (2):210-14.

24. Noorhassim I, Rampal KG. Multiplicative effect of smoking and age on hearing impairment. Am J Otolaryngol 1998; 19(4):240-3.

25. Chang J, Ryou N, Jun HJ, Hwang SY, Song JJ, Chae SW. Effect of cigarette smoking and passive smoking on hearing impairment: data from a population-based study. PloS one. 2016; 11 (1):e0146608. doi: 10.1371/journal.pone.0146608.

26. Sharabi Y, Reshef-Haran I, Burstein M, Eldad A. Cigarette smoking and hearing loss: lessons from the young adult periodic examinations in Israel (YAPEIS) database. Isr Med Assoc J 2002; 4 (12):1118-20.

27. Sumit AF, Das A, Sharmin Z, Ahsan N, Ohgami N, Kato $M$, et al. Cigarette smoking causes hearing impairment among Bangladeshi population. PloS one. 2015;10(3):e0118960. doi: 10.1371/ journal.pone.0118960.

28. Ohgami N, Kondo T, Kato M. Effects of light smoking on extra-high-frequency auditory thresholds in young adults. Toxicol Ind Health 
2011; 27(2):143-7. doi: 10.1177/074823371 0382539.

29. Cruickshanks KJ, Tweed TS, Wiley TL, Klein BE, Klein R, Chappell R, et al. The 5-year incidence and progression of hearing loss: the epidemiology of hearing loss study. Arch Otolaryngol Head Neck Surg 2003; 129(10):1041-6.

30. Nakanishi N, Okamoto M, Nakamura K, Suzuki K, Tatara K. Cigarette smoking and risk for hearing impairment: a longitudinal study in Japanese male office workers. J Occup Environ Med 2000; 42 (11):1045-9.

31. Thomas GB, Williams CE, Hoger NG. Some nonauditory correlates of the hearing threshold levels of an aviation noise-exposed population. Aviat
Space Environ Med 1981; 52(9):531-6.

32. Mizoue T, Miyamoto T, Shimizu T. Combined effect of smoking and occupational exposure to noise on hearing loss in steel factory workers. Occup Environ Med 2003; 60(1):56-9.

33. Itoh A, Nakashima $\mathrm{T}$, Arao $\mathrm{H}$, Wakai $\mathrm{K}$, Tamakoshi A, Kawamura T, et al. Smoking and drinking habits as risk factors for hearing loss in the elderly: epidemiological study of subjects undergoing routine health checks in Aichi, Japan. Public health. 2001; 115(3):192-6.

34. Carmelo A, Concetto G, Zirilli A, Antonietta TM, Graziella D, Renato B, et al. Effects of cigarette smoking on the evolution of hearing loss caused by industrial noise. Health. 2010; 2(10):1163-69.

AUTHOR AFFILIATION:
Dr. Shakil Ahmed Shaikh
Department of Physiology
CMH Hyderabad, Sindh-Pakistan.
Dr. Zulfiqar Ali Laghari
Professor, Department of Physiology
University of Sindh Jamshoro, Sindh-Pakistan.
Dr. Salma Farrukh Memon (Corresponding Author)
Associate Professor, Department of Physiology
Liaquat University of Medical and Health Sciences
Jamshoro, Sindh-Pakistan.
Email: memon_salma@hotmail.com
Dr. Muhammad Ali Bhatti
Combined Military Hospital Hyderabad, Sindh-Pakistan.

